\title{
The impact of older siblings on the language environment and language development of bilingual toddlers
}

\author{
Danai Tsinivits and Sharon Unsworth*(i) \\ Centre for Language Studies, Radboud University, Nijmegen \\ ${ }^{\star}$ Corresponding author. E-mail: s.unsworth@let.ru.nl
}

(Received 06 February 2020; revised 23 September 2020; accepted 01 October 2020; first published online 31 December 2020)

\begin{abstract}
Previous research has suggested that the language development of bilingual children benefits from more exposure and opportunities for language use. Typically, this research has used aggregated measures of exposure and use. The role of specific interlocutors and in particular older siblings has received comparatively little attention. In this study, we examine the impact of having an older sibling on the language environment and language development of a group of 31 bilingual Greek-Dutch toddlers aged 16 to 30 months growing up in the Netherlands. Approximately half $(n=14)$ of the toddlers had an older sibling. With respect to language environment, toddlers with older siblings were in general found to hear and use more Dutch at home than their first-born peers. There were however no differences between the two groups of toddlers in terms of parental language use. With respect to language development, toddlers with older siblings were found to score higher than first-born peers on measures of Dutch receptive vocabulary, productive vocabulary, and morphosyntactic complexity. For Greek, no such differences were observed. The findings are discussed in light of factors including family constellation, parental language proficiency, bilingual parenting strategies, and the wider sociolinguistic context.
\end{abstract}

Keywords: bilingual language development; input; language environment; older siblings

Bilingual families come in all shapes and sizes, with the consequence that one characteristic feature of bilingual language experience and language development is variability. Numerous studies have investigated how variability in bilingual children's rate of acquisition in each of their two languages is related to variability in their experience with these languages (e.g., de Houwer, 2009; Gathercole \& Thomas, 2009; Scheele, Leseman, \& Mayo, 2010; see Unsworth, 2016, for overview). The majority of these studies have focused on the relation between children's developing language skills and the amount of exposure or input (e.g., Gutiérrez-Clellen \& Kreiter, 2003; Thordardottir, 2011; Unsworth, 2013), and the focus has generally been on exposure from parents unrestricted re-use, distribution, and reproduction in any medium, provided the original work is properly cited. 
and/or more general measures of input quantity such as the average proportion of weekly exposure to a given language (Sorenson-Duncan \& Paradis, 2020). Relatively little is known about the effect of exposure from other interlocutors at home, such as older siblings, even though having older siblings clearly impacts on children's daily life at home. In this study, we examine the impact of having an older sibling on patterns of family language use and on developing language proficiency in a group of bilingual Greek-Dutch toddlers.

Research on the role of birth order in monolingual children suggests that birth order impacts on language development, although the results are mixed. Several studies have found that first-born children have better language skills than secondborn children (e.g., Bornstein, Leach, \& Haynes, 2004; Hoff, 2003; Zambrana, Ystrom, \& Pons, 2012; Zyrianova, Chertkova Yu, \& Pankratova, 2013). At the same time, however, there are also studies showing the reverse pattern (e.g., Barton \& Tomasello, 1991; Oshima-Takane, Goodz, \& Derevensky, 1996), with the more advanced language development of children with older siblings attributed to differences in language exposure. More specifically, Oshima-Takane et al. (1996) found that in addition to child-directed speech, second-born children were exposed to more complex, indirect speech in the form of overheard conversations between their parents and older siblings and that this contributed to their comparatively more advanced development in the acquisition of personal pronouns. There are also a number of studies with monolingual families showing no relation between sibling status and language development (Berkowitz, 2000; Skeat et al., 2010).

Research on bilingual language development is more limited but has shown that bilingual children may face different language experiences depending on birth order (e.g., Barron-Hauwaert, 2011). For example, in a study of simultaneous bilingual Spanish-English toddlers' language development, Bridges and Hoff (2014) found that children with older, school-aged siblings received more input to the majority language (English) at home than children without older siblings, and that this was positively related to their development in that language as measured by the MacArthur Bates Communicative Developmental Inventory (CDI; Fenson et al., 2007). Similar results have been found for sequential bilingual children. Sorenson Duncan and Paradis (2020) found that input from older siblings was positively related to the vocabulary, inflectional morphology, and narrative macrostructure of 5-year-old child second language (L2) learners of English with various L1 languages (Mandarin, Spanish, and Hindi). The authors speculated that as a result of their educational experiences, older siblings may provide better quality input than the L2 input provided by mothers, and as such, an increase in sibling input was related to more advanced language development whereas no such relation was found for maternal input.

The presence of older siblings in bilingual families has been found not only to impact on the amount of exposure available to younger children but also on the extent to which they use the two languages in question. In line with Sorenson Duncan and Paradis (2020), Rojas et al. (2016) found that children's language use (i.e., input from and output to) with siblings and peers was a better predictor of their scores than their language use with parents for both of their languages (i.e., Spanish and English). However, when language input and output were disaggregated, it appeared that what mattered most was how much the 4- to 6-year-old 
children in their study spoke English (i.e., the majority language) when speaking to their older siblings and peers, rather than how much the older children spoke English in the input they provided to their younger siblings. This finding is in line with other studies reporting that the language(s) used between siblings may differ from the language(s) used in child-parent interactions (Caldas, 2006; see also Study 1 in Bridges \& Hoff, 2014).

Having an older, school-aged sibling may affect the language input available to younger bilingual children simply by virtue of there being an additional interlocutor in the household. At the same time, the impact of older siblings may extend to patterns of language use in the household more generally. For example, Bridges and Hoff (2014) observed that it was not only older siblings who used more English than Spanish when speaking to the toddlers (on average 70\%): mothers of older school-aged children also used more English when speaking to their toddlers compared to mothers with only a toddler. Relatedly, in a study on Turkish-Dutch bilingual children in the Netherlands, Prevoo, Mesman, IJzendoorn, and Pieper (2011) found that Turkish-speaking mothers increased their use of Dutch while addressing their toddlers when these children began attending Dutch-language early childhood education. The increase was particularly significant when the families lived in a neighborhood with a low percentage of Turkish immigrants, suggesting that when more of the majority language is present in a child's wider sociolinguistic context, parents may be more inclined to use the majority language at home. A greater use of the majority language by parents in families with more than one child has also been reported in a larger scale survey of patterns of family language use (Barron-Hauwaert, 2011) as well as in case studies of multilingual (Cantone, 2019) and bilingual children (Kopeliovich, 2013).

Not all studies have observed a positive relation between exposure from older siblings and bilingual children's language development, however. In a study of sequential bilingual Cantonese-English 3-year-old children, Taylor and Kan (2018) found that children with older siblings who spoke English and Cantonese to roughly the same degree did not have significantly higher vocabulary scores in English than children whose older siblings spoke (almost) exclusively in Cantonese. As the authors noted in their explanation for these findings, language use between siblings may interact in complex ways with other factors, including the older siblings' school experience and the family's cultural beliefs and practices. More generally, the impact of older siblings may differ depending on where they were born (Shin, 2002; Stevens \& Ishizawa, 2007) and on parental language strategies. Parents may, for example. explicitly enlist help from their older children to teach the minority language to their younger siblings (Kennedy \& Romo, 2013).

Where a positive impact of older siblings on the majority language development of younger children has been observed, it has largely been found to come at the expense of the minority (or heritage) language (Bridges \& Hoff, 2014; Rojas et al., 2016). For example, Bridges and Hoff (2014) observed that both at 22 months and again at 30 months, vocabulary scores in Spanish were related to sibling status: the bilingual toddlers in their study with older siblings knew significantly fewer words in Spanish than their first-born peers. For grammatical development (MLU3), the pattern was slightly different, with the difference between toddlers with and without older siblings emerging at 30 months only. The older siblings in 
this study were reported as using English most of the time (around 70\%) when addressing the younger children.

In contrast, Taylor and Kan (2018) found an advantage for children with older siblings in the minority language, at least for one of the outcomes in their study. More specifically, 3-year-old bilingual children's fast-mapping skills in Cantonese were found to be significantly better when their older siblings spoke Cantonese to them (almost) all the time as opposed to children whose older siblings addressed them in both Cantonese and English. At the same time, no such advantage was found for vocabulary scores in Cantonese, where no relation was observed between vocabulary and exposure from older siblings. One of the reasons put forward by the authors to explain this finding is that the amount of L2 (i.e., English) exposure provided by older siblings in these predominantly Cantonese-speaking families was not enough to have a negative impact on the minority language.

In sum, there is an emerging body of evidence that older siblings may have a significant impact on both the language environment and the language development of young bilingual children. However, the number of studies remains limited, as does the language combinations that have been investigated. Furthermore, the focus has mostly been on the younger siblings' majority language development. The extent to which bilingual children's minority language development is related to the presence of older siblings in the family remains unclear. Taken together, these findings suggest that the role of older siblings in the bilingual language development of toddlers warrants further investigation.

\section{Research questions and hypotheses}

The aim of this study is to replicate and expand the results of previous studies by examining the influence of older siblings on the language environment and language development of Greek-Dutch bilingual children aged 16 to 30 months growing up in the Netherlands. Following Bridges and Hoff (2014), among others, our first hypothesis is that older siblings are a significant source of language-advancing input in the majority language (i.e., Dutch). This leads to the following three predictions:

1. Bilingual toddlers with older siblings will be exposed to more Dutch (and hence less Greek) at home than bilingual toddlers without older siblings.

2. Bilingual toddlers with older siblings will also use more Dutch (and hence less Greek) at home than bilingual toddlers without older siblings.

3. Bilingual toddlers with older siblings will have more advanced Dutch language skills than bilingual toddlers without older siblings.

On the basis of Bridges and Hoff (2014), our second hypothesis is that having older, school-aged siblings will at the same time have a negative impact on bilingual toddlers' minority (or heritage) language development. We therefore predict that

4. Bilingual toddlers with older siblings will have less advanced Greek language skills than bilingual toddlers without older siblings. 


\section{Method}

\section{Participants}

Participants were 32 Dutch-Greek bilingual children aged between 16 and 30 months $(M=24.75, S D=4.89 ; 12$ boys, 20 girls). Twenty-nine were resident in the Netherlands and 3 in Flanders, the Dutch-speaking area of Belgium. Recruitment was conducted via social media and by word of mouth. Most of the 56 caregivers (32 mothers, 24 fathers) were highly educated (college diploma and/or master's or doctoral diploma), and with the exception of four fathers, all had completed (at least) high school.

All children were exposed to both Dutch and Greek to some degree from birth, but the onset of systematic exposure to Dutch varied from age 3 to 20 months $(M=5.09, S D=6.35)$, depending on the start of daycare or an in-house childminder. On average, cumulative exposure (in years) in Greek was greater $(M=1.28, S D=0.44)$ than in Dutch $(M=0.78, S D=0.45)$. At the time of testing, most $(N=25)$ children attended Dutch-language daycare, one had an in-house Dutch-speaking childminder, while four stayed at home with their mother and two with their father. None of the participating families had other adults living in their homes.

There were 18 children with no siblings and 14 children with older siblings. The two groups did not differ in age (no siblings: $M=24.56, S D=4.90$; with siblings: $M=25, S D=5.05), t(30)=-0.251, p=.803 d=0.089$. Of the 14 children with older siblings, 13 of them had only one older sibling and one had three older siblings (triplets, aged 15). The age of the older siblings ( $N=6$ boys, $N=10$ girls) varied between 4 and 15 years $(M=7.5 ; S D=3.2)$. According to the parents, the time that older siblings spent with the toddlers on a weekly basis varied from $1.5 \mathrm{hr}$ to approximately $18 \mathrm{hr}(M=11.3 ; S D=3.69)$. All the older siblings attended schools where Dutch was the language of instruction and were reported by parents as having nativelike proficiency in both languages.

More than half of the older siblings were reported as using both languages equally $(N=6)$ or almost equally $(N=4)$ when addressing their younger siblings, while the remaining 6 older siblings used mostly Dutch during sibling interaction. Regarding the toddlers' language use toward their older siblings, parents reported that 11 of them used Greek and Dutch equally often, and the remaining 3 spoke exclusively in Dutch during sibling interaction.

An overview of the parents' native languages and their self-rated proficiency in their nonnative language is provided for the two groups of toddlers (i.e., those with older siblings and those without older siblings) in Table 1 . There was no significant difference between the two groups in terms of the number of parents who were native speakers of Greek, $\chi^{2}(1, N=32)=1.66, p=.198$. With the exception of one mother who had herself grown up bilingually (child 16, see more detailed version of Table 1 in Appendix A), all had learned the other language as an adult. The average age of onset to Dutch as an L2 was 28.62 years $(S D=4.85$; range 22 to 42 years) and for Greek this was comparable $(M=29.27, S D=6.57$; range 18 to 42 years). The nonnative speakers of Dutch were reported as being more proficient in their L2 than the nonnative speakers of Greek, which is perhaps unsurprising given that the families were resident in the Netherlands at the time of testing. 
Table 1. Distribution of parents' native language and parental ratings of fluency in their nonnative language within each group (i.e., toddlers with siblings and toddlers without siblings)

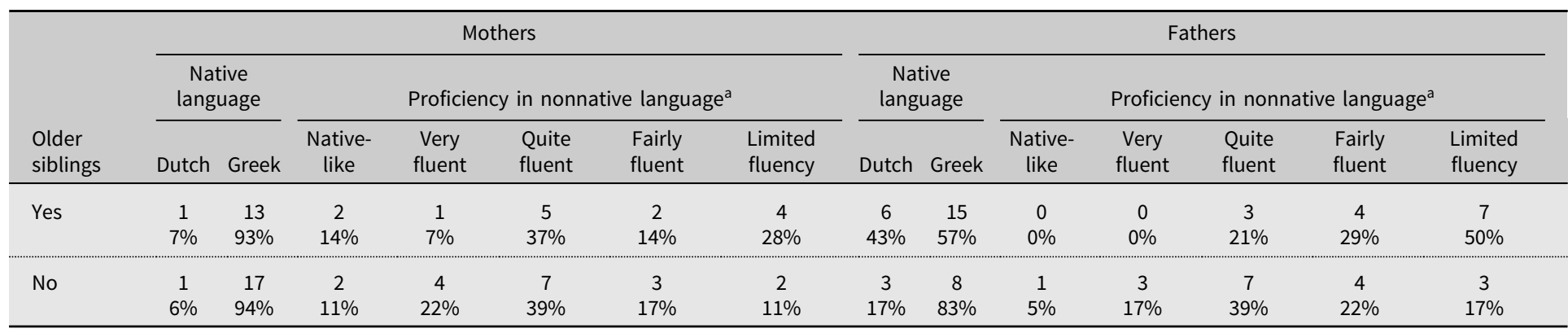

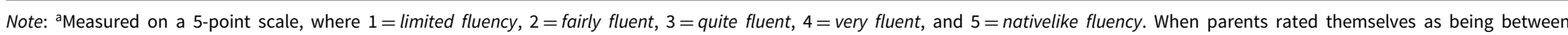
categories, the values were averaged. 


\section{Materials}

CDIs

Measures of children's language development were collected using the CDI in Greek (Markodimitraki, Papailiou, Politimou, \& Franco, 2015) and in Dutch (Zink \& Lejaegere, 2002). The CDI is a caregiver-report instrument in which caregivers are asked to indicate the extent to which children understand and produce certain words and grammatical structures. While no reliability statistics are available for the two versions used here, both the English and Spanish versions have been shown to be both valid and reliable in bilingual populations (Dale, 1991; Dale, Bates, Reznick, \& Morisset, 1989; Marchman \& Martínez-Sussmann, 2002). Both the Dutch and the Greek adaptions are suitable for children between 16 and 30 months old.

Each instrument yields a measure of receptive vocabulary (i.e., number of words which the child understands), a measure of productive vocabulary (i.e., number of words which the child produces), as well as the mean length of the three longest utterances (MLU3) that the child produces in the target language. In the current study, MLU3 was measured through morphemes (e.g., Ezeizabarrena \& Garcia Fernandez, 2018). Given that we are not directly comparing Greek and Dutch with each other, any issues concerning the cross-language comparability of MLU in morphemes are not directly relevant here.

There are two important differences between the Dutch and the Greek versions of the CDI. First, the Dutch version includes two measures of grammatical complexity (Woordvormen "word forms" and Zinnen "sentences"), whereas the Greek version does not contain any such measure. Second, the number of items in the vocabulary list varies: the Greek version contains 412 items, while the Dutch one has 702 items. For this reason, the two instruments are not directly comparable; however, given that our analyses do not involve any direct cross-language comparisons, we do not consider this problematic (see also Hoff et al., 2012, fn. 1, p. 9). A detailed comparison of the two versions is provided in Appendix A. Each CDI was completed by the caregiver who was fluent in that language and was thus aware of the child's abilities.

The bilingual language experience calculator (BiLEC, Unsworth, 2013)

The BiLEC is a detailed parental questionnaire containing both quantitative and qualitative measures of language exposure. More specifically, caregivers were asked to indicate where and with whom the child spends time during an average day in the week and at the weekend, for how long, and the proportion of Greek and Dutch each person uses when addressing the child, as well as the proportion of Greek and Dutch the child uses with them. Information was also gathered about patterns of language exposure in the past as well as parents' proficiency levels in the two languages. Two composite measures were derived from these questionnaire data for the analysis (Unsworth, 2013): overall current exposure to Dutch at home (in \%) and overall current use of Dutch at home (in \%). For both of these measures, the proportion of Dutch spoken by each interlocutor was weighted according to the amount of time each person spent with the child. Both measures are relative, meaning that whenever a child was not reported as hearing or using Dutch, she heard or used Greek. 
We also included the average proportion of Dutch used by both parents in our analyses; this value was not weighted.

\section{Procedure}

After the caregivers had given written consent to participate in the study, they were sent links to digital versions of the CDIs (in Greek and Dutch) via e-mail, along with detailed instructions on how to complete them. The BiLEC was administered in a conversation between one of the caregivers and the first author either via Skype or in person. This lasted between 15 and $30 \mathrm{~min}$.

\section{Analysis}

The data for most of the outcome variables were not normally distributed and therefore did not meet the assumptions for statistical testing using parametric tests. For this reason, comparisons between the two groups (i.e., toddlers with older siblings and toddlers without) were made using the nonparametric Mann-Whitney test (Field, 2009). Because multiple comparisons were made, the Holm-Bonferroni sequential procedure (Bland \& Altman, 1995) was used to correct for the familywise error rate. The four sets of analyses relating to each of our four research questions (i.e., testing the relation between sibling status and language input, language use, Dutch language proficiency, and Greek language proficiency, respectively) were considered separate families (following Lakens, 2016).

\section{Results}

\section{Sibling status and language environment}

The average levels of exposure to Dutch at home (overall), from parents, and from older siblings are presented for the two groups of toddlers (i.e., children with older siblings and children without older siblings) in Figure 1.

The overall level of Dutch exposure at home was significantly greater for toddlers with older siblings $(M d n=40)$ than for toddlers without older siblings $(M d n=24.5), U=184.5, p=.025, \eta^{2}=.154$. Concerning relative Dutch exposure from parents only (i.e., the average of maternal and paternal input), there was no significant difference between families with $(M d n=42.5)$ and without older siblings $(M d n=20), U=152, p=.338, \eta^{2}=.03$. The average levels of Dutch language use by toddlers at home (overall), when addressing parents, and when addressing older siblings, is given in Figure 2.

Overall Dutch language use at home was significantly greater for toddlers with older siblings $(M d n=49)$ than for toddlers without older siblings $(M d n=20)$, $U=180.5, p=.037, \eta^{2}=.134$. In contrast, there was no significant difference in how much toddlers used Dutch when speaking to their parents (toddlers with older siblings: $M d n=50$; toddlers without older siblings: $M d n=20$ ); $U=166, p=.135$, $\eta^{2}=.072$. 


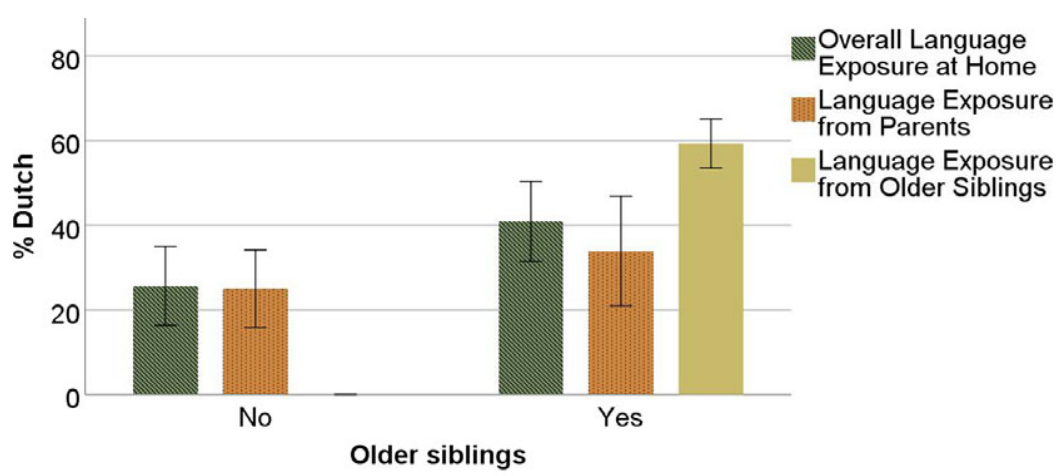

Error Bars: $95 \% \mathrm{Cl}$

Figure 1. Mean levels of overall exposure at home, language exposure from parents, and from older siblings, for toddlers without older siblings and toddlers with older siblings.

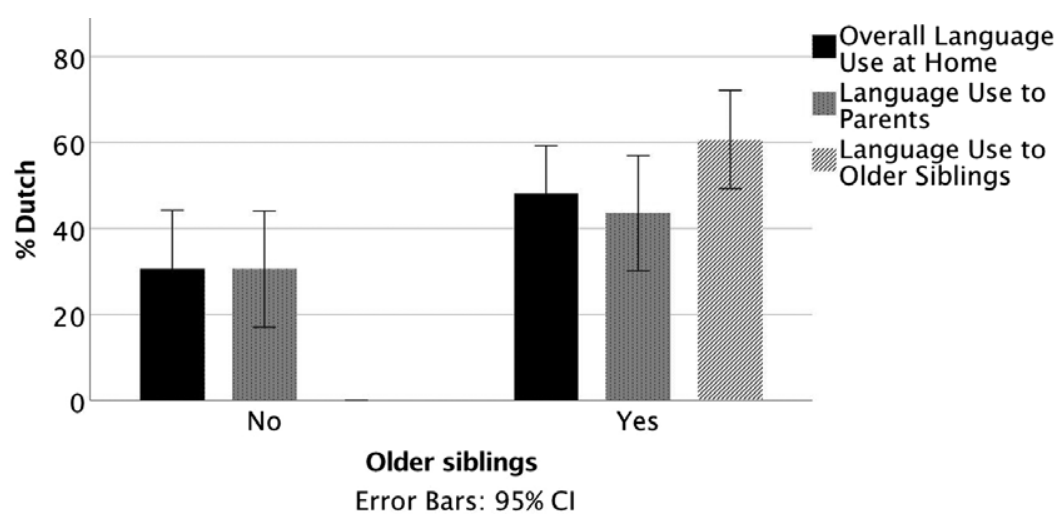

Figure 2. Mean levels of overall language use at home, language use to parents, and to older siblings, for toddlers without older siblings and toddlers with older siblings.

\section{Sibling status and Dutch language proficiency}

The overall range, mean, and standard deviation for the measures of children's language skills in Dutch are presented in Table 2, and for the two groups separately in Figures 3 and 4.

Toddlers with older siblings $(M d n=633.5)$ had significantly larger receptive vocabularies than children without older siblings $(M d n=323.5), U=211, p=.001$, $\eta^{2}=.407$. Toddlers with older siblings were also found to have significantly larger productive vocabularies $(M d n=599)$ than children without older siblings $(M d n=70), U=214, p=.000, \eta^{2}=.349$. A similar pattern was found for MLU3: children with older siblings $(M d n=3.85)$ were found to have significantly longer utterances than children without older siblings $(M d n=1.7), U=181, p=.037$, $\eta^{2}=.136$ 
Table 2. Descriptive statistics for measures of Dutch and Greek language Skills in 16- to 30-month old bilingual Dutch-Greek children ( $\mathrm{N}=32)$

\begin{tabular}{|c|c|c|c|}
\hline Language & Receptive vocabulary & Productive vocabulary & MLU3 \\
\hline \multicolumn{4}{|l|}{ Dutch } \\
\hline$M$ & 435.44 & 271.13 & 2.86 \\
\hline$S D$ & 213.08 & 258.37 & 2.78 \\
\hline Range & $38-702$ & $0-686$ & $0-11.4$ \\
\hline \multicolumn{4}{|l|}{ Greek } \\
\hline$M$ & 313.25 & 173.78 & 7.07 \\
\hline$S D$ & 106.06 & 157.15 & 7.03 \\
\hline Range & $41-412$ & $4-412$ & $0-28.4$ \\
\hline
\end{tabular}

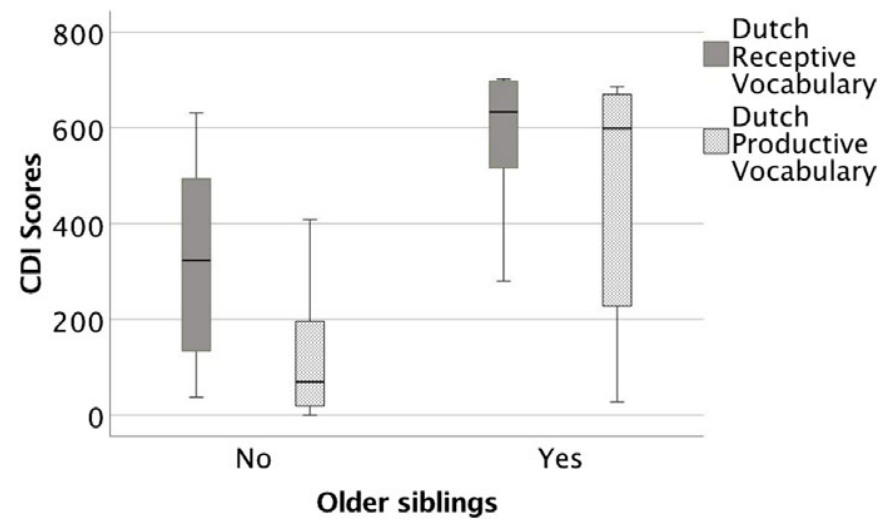

Figure 3. Receptive and productive vocabulary scores in Dutch for toddlers without older siblings and toddlers with older siblings.

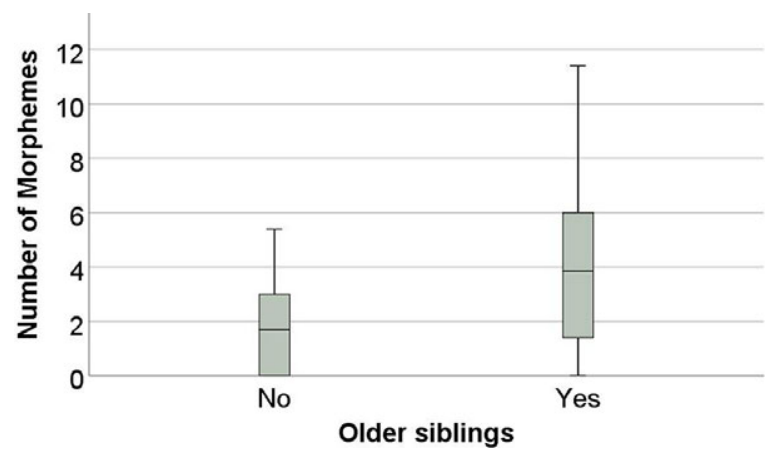

Figure 4. Mean length of utterance (MLU3) in Dutch for toddlers without older siblings and toddlers with older siblings. 


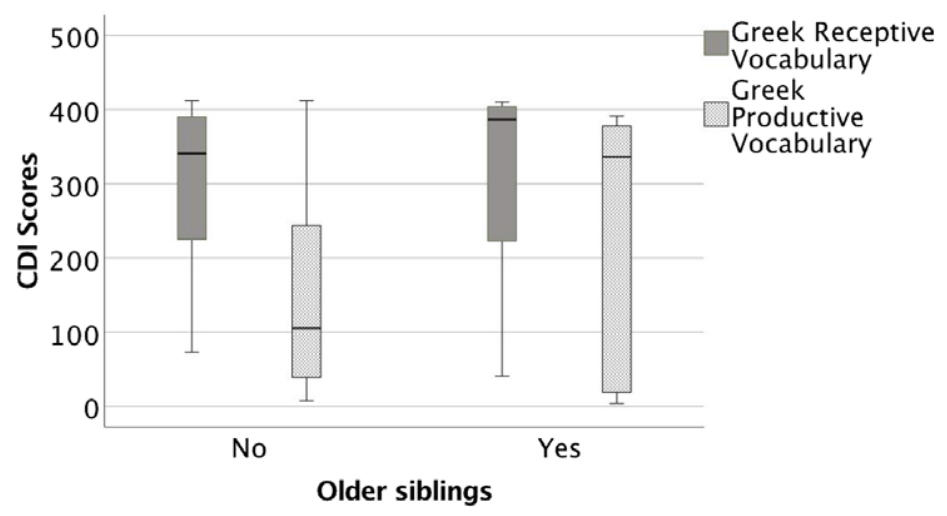

Figure 5. Receptive and productive vocabulary scores in Greek for toddlers without older siblings and toddlers with older siblings.

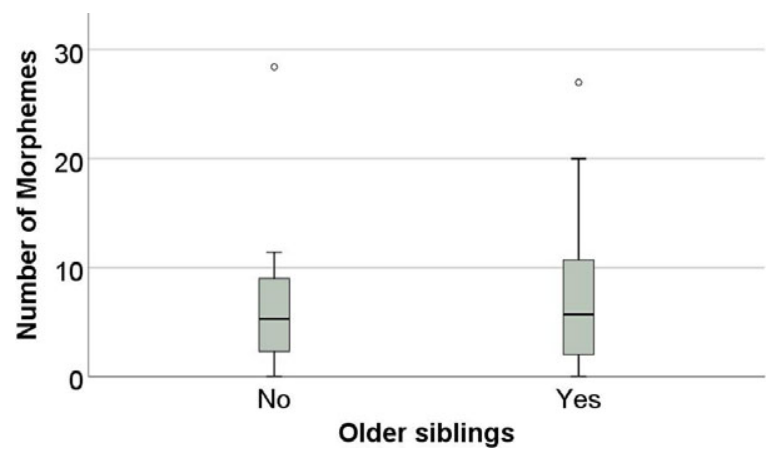

Figure 6. Mean length of utterance (MLU3) in Dutch for toddlers without older siblings and toddlers with older siblings.

\section{Sibling status and Greek language proficiency}

The range, mean, and standard deviation for the measures of children's language skills in Greek are presented in Table 2. These are presented for the two groups separately in Figures 5 and 6.

For receptive vocabulary, there was no significant difference between toddlers with older siblings $(M d n=386.5)$ and toddlers without $(M d n=341), U=143.5$, $p=.512, \eta^{2}=.014$. While visual inspection of the data (cf. Figure 5) revealed a trend for toddlers with older siblings to have larger productive vocabularies in Greek $(M d n=336)$ than toddlers without $(M d n=105.5)$, this difference was not significant, $U=144, p=.512, \eta^{2}=.015$. Regarding grammatical complexity (i.e., MLU3), there was also no significant difference between toddlers with older siblings $(M d n=5.7)$ and toddlers without $(M d n=5.3), U=137.5, p=.667$, $\eta^{2}=.006$. 


\section{Summary}

In general, bilingual Greek-Dutch toddlers with older siblings were found to be exposed to more Dutch at home relative to Greek than toddlers without older siblings. This was only the case when both siblings and parents were included in the measure of language exposure. Effect sizes were small. Parental input alone did not differentiate between toddlers with and without older siblings. The same held for patterns of language use: the presence of an older sibling was positively related to toddlers' overall relative proportion of Dutch use at home, but when only the toddlers' language use to parents was considered, there was no significant relation with sibling status. Toddlers with older siblings had more advanced Dutch language skills on all three measures. Effect sizes were small to medium. In contrast, no significant differences were found for Greek language skills.

\section{Discussion}

The current study examined the influence of older siblings on the language environment and language development of Greek-Dutch toddlers growing up in the Netherlands and Flanders, Belgium, by comparing a group of toddlers with older siblings to a group of first-born toddlers on properties of their language environment (i.e., language exposure and use) and several aspects of the Dutch and Greek language proficiency (i.e., receptive and productive vocabulary, and MLU3). About half of the Greek-Dutch bilingual toddlers in our sample had older siblings. The older siblings in our sample varied in age and likely in part as a result, in how much time they spent with their younger brothers and sisters. They also varied in how much they used each of the two languages in sibling interaction but the majority used both Dutch and Greek. We factored these differences into our overall measures of language exposure and use by weighting each person's contribution accordingly.

\section{Older siblings and majority language exposure and use}

Following previous research (e.g., Bridges \& Hoff, 2014; Sorenson Duncan \& Paradis, 2020), our first hypothesis was that older siblings would be a significant source of language-advancing input in the majority language (i.e., Dutch). This led to two predictions concerning the relation between older siblings and toddlers' language environment, namely, that toddlers with older siblings would be exposed to and use more Dutch (and hence less Greek) at home than bilingual toddlers without older siblings. This turned out to be the case. Our study therefore replicates previous results from Spanish-English bilingual toddlers (Bridges \& Hoff, 2014) using the same instruments to measure language development (i.e., CDI) for a different language combination in a different context. It furthermore demonstrates that this difference holds for both input to and output from the child. In other words, second-born children appear to have different bilingual experiences not only in terms of which languages they hear but also in terms of which languages they use.

At the same time, when our measures of language exposure and use were restricted to child-parent interactions, there was no such significant relation with sibling status. The difference between these two ways of operationalizing language 
exposure and use suggests that it is the older siblings who contribute to the overall increase in the use of Dutch at home. ${ }^{1}$ The finding that the parent-only measures were not significantly related to sibling status differs from previous research, where patterns of parental language use have been found to differ for first- versus secondborn children (Barron-Hauwaert, 2011; Bridges \& Hoff, 2014). There are at least two possible explanations for these differences, relating to the specific characteristics of our sample and in particular the languages in question.

In the families in our sample, mothers were not always the primary caregiver. For this reason, we included both parents in our measures of exposure and use. This contrasts with, for example, the families in Bridges and Hoff (2014). There only mothers were included; these were all native speakers of Spanish, and given that they were highly educated and living in the United States, likely also (highly) proficient in English. About a third of the parents in our sample were native speakers of Dutch, most of whom had limited or no proficiency in Greek. Similarly, while the Greek native-speaker parents were in general more proficient in their nonnative language than the native speakers of Dutch, in many cases their proficiency in Dutch was also limited. This is no doubt a reflection of the status of the two languages in the wider sociolinguistic context: Greek and Dutch are both languages that are not widely spoken outside of the countries in question, and hence are generally only learned when the need arises, for example, for reasons relating to immigration and/or a relationship. This general lack of bilingual proficiency among the parents in our sample means that they were more likely to stick to their native language and, hence, in the case of the native speakers of Greek, be less amenable to influence from their Dutch-speaking eldest child(ren). Taken together, these findings suggest that while school-aged siblings may bring more of the majority language into the home, the extent to which this leads to increases in parental use of that language will be tempered by their own proficiency. It may also depend on the language strategy that parents adopt, an issue to which we return below.

It is possible that parental language proficiency may also account for the lack of any significant relation between children's language use and sibling status. Put simply, if parents have limited proficiency in Dutch (or Greek), children will, in most cases, stick to the language in which the parent is proficient. It turned out that the parents of first-born toddlers who were native speakers of Greek tended to have better proficiency in Dutch than the native Greek-speaking parents of toddlers with an older sibling (cf. Table 1). As such, children in this group could have had more opportunity to use Dutch. Once again, while perhaps a somewhat obvious observation (i.e., that children are less likely to use a language to a parent who has limited proficiency in that language), this finding illustrates how gaining a full understanding of the patterns of language exposure and use in bilingual families requires detailed investigation of the relations between different variables. The relatively small sample size in the present study in a certain sense makes it easier to explore these relations, but for a comprehensive investigation, more data is needed.

\section{Older siblings and majority language development}

Our third prediction concerning older siblings as a source of Dutch-advancing input was that bilingual toddlers with older siblings would have more advanced Dutch 
language skills than bilingual toddlers without older siblings. This prediction was borne out for all three measures, that is, receptive vocabulary, productive vocabulary, and grammatical complexity as measured by MLU3. On the assumption that sibling status is the crucial difference between these two groups, these findings replicate and provide further support for earlier findings on the role of older siblings (Bridges \& Hoff, 2014; Rojas et al., 2016; Sorenson Duncan \& Paradis, 2020; but cf. Taylor \& Kan, 2018). Older siblings are a useful (additional) source of input. This may be because their presence means more input but also because they may provide different input from their parents (Deutsch, Wagner, Burchardt, Schulz, \& Nakath, 2001); further research is necessary to establish whether this the case.

These findings are also in line with research showing that input from many/multiple speakers is helpful in bilingual language development (Place \& Hoff, 2011), and especially for the minority language (Gollan, Starr, \& Ferreira, 2015). Using a language with more people may also increase the functional value of that language and thus promote children's language acquisition (Alba, Logan, Lutz, \& Stults, 2002; Gathercole \& Thomas, 2009). Furthermore, as noted above, sibling interactions provide more opportunities for children to practice and produce speech, which in turn may result in more (implicit) feedback, something which may specifically contribute to the development of their productive skills (Pearson, 2007).

\section{Older siblings and minority language development}

Our second hypothesis was that having older, school-aged siblings would have a negative impact on bilingual toddlers' minority (or heritage) language development. This led to our fourth and final prediction, namely, that bilingual toddlers with older siblings would have less advanced Greek language skills than bilingual toddlers without older siblings. This prediction was not borne out in our data, however. Our analyses failed to reveal any significant differences between the two groups on any of the measures of Greek language proficiency, and where a trend was observed descriptively (cf. productive vocabulary scores in Figure 5), this was in the opposite direction, that is, the toddlers with older siblings appeared to have better scores than the toddlers without. Note that this was the case even though the toddlers with older siblings heard and used less Greek (and more Dutch) overall than their first-born peers.

While failing to find a significant difference does not mean that there is no difference, especially given our relatively small sample size, these findings contrast with previous research (e.g., Bridges \& Hoff, 2014; Rojas et al., 2016), where children with older siblings have been found to have significantly less advanced proficiency in their minority language than first-born children. There are a number of reasons why the toddlers with older siblings in our sample may not differ from their first-born peers in terms of their proficiency in Greek. These relate to family constellation, bilingual parenting strategies, and patterns of language use within the wider sociolinguistic context.

Many of the children in our sample were being raised in Greek-only households (cf. Bridges \& Hoff, 2014, where all participants were from bilingual households). In such "minority language at home" families, parents are often invested in maintaining the heritage language and culture (Kopeliovich, 2010; Park \& Sarkar, 2007); 
in various countries around the world (e.g., Australia), this has been found to especially hold for Greek communities (Chatzidaki, 1996; Gogonas \& Kirsch, 2016; Holmes, Roberts, Verivaki, \& Aipolo, 1993; Smolicz, Secombe, \& Hudson, 2001). Under these circumstances, older children often address their younger siblings in the minority language during family conversations involving both parents and younger siblings, whereas when siblings interact alone, they tend to use the majority language (Kheirkhah, 2016). Given that several of the older siblings in our sample were born in Greece, they were likely quite proficient in Greek and this may also have contributed to greater and richer input in their interaction with their younger siblings (Caldas, 2006; Shin, 2002; Stevens \& Ishizawa, 2007), as may their maturity, for some children at least (Oshima, et al., 1996). More generally, encouraged by parents, older siblings may also adapt the role of a model or "teacher" toward their younger siblings (Kennedy \& Romo, 2013), by correcting and improving their sibling's language use and performance in both languages (Barron-Hauwaert, 2011; Kheirkhah \& Cekaite, 2018). While we do not know whether such bilingual parenting strategies were commonplace in the families in our study, the observation that toddlers' minority language development was not significantly-and crucially, not negatively-related to the presence of school-aged siblings is certainly consistent with their use.

None of the families in our sample had other relatives living in their homes at the time of testing, but many reported lengthy visits to Greece during holidays where children (both the toddlers tested here and their older siblings) were exposed to predominantly Greek language input over an extensive period of time. The beneficial role of grandparents and other relatives in bilingual language development has been observed elsewhere (e.g., Melo-Pfeifer, 2014), and this may have counteracted any potentially negative impact of hearing more Dutch input at home. Several Greek-speaking parents in our sample reported switching to Dutch when outside of the home (e.g., in the playground), but many families tended to socialize with other Greek-speaking families, which meant that Greek-speaking peers were also available to the toddlers in our sample. While the research on the role of peers in bilingual language development is limited, the available studies suggest that (native speaker) input from peers may be an important factor in acquisition of the majority language (Jia \& Fuse, 2007; Palermo et al., 2014; Rojas et al., 2016). Our data suggest, albeit indirectly, that the role of input from peers on the minority language warrants further investigation. Socializing with other Greek-speaking families, in some cases in combination with limited proficiency in Dutch, may also have restricted parental use of Dutch in the home (Prevoo et al., 2011).

\section{Implications, limitations, and conclusion}

The findings of the present study confirm what many parents report anecdotally: older children can have an important effect on the language development of their younger siblings. To the extent that older children use both languages, our findings demonstrate that having an older sibling is positively related to majority language development but it is not necessarily negatively related to the minority (or heritage) language. This may depend on factors such as parental language proficiency, family constellation, and the wider sociolinguistic context. In many cases, it is minority 
language development that parents are frequently concerned about, especially once children reach school-age and the majority language often becomes more dominant, with the result that in many cases in children stop using the minority language altogether (de Houwer, 2007). Our findings suggest, albeit indirectly, that encouraging older siblings to use the minority language with younger children in the family (at least some of the time) may play an important role in promoting minority language development, not only because they will provide more input (and potentially different input from parents), but also because as an additional interlocutor, they offer younger siblings the opportunity to use the language. Furthermore, our findings may offer parents of bilingual toddlers some hope in that sense that even when older siblings may bring more Dutch input in the home, this apparently does not inevitably lead to significantly lower Greek language skills compared with toddlers growing up in single-child households, at least not at this young age. Whether differences arise in the longer term requires further research.

To fully understand the complex relations between these different variables, more data are needed. As a result of the relatively small sample size, the present study was only able to investigate the relation between sibling status and a limited number of variables relating to children's language environment and their language development. There are several variables which were not included here but warrant further investigation in relation to sibling status. These include input quality and preliteracy activities. The bilingual children in the present study were growing up in an environment where one language was culturally dominant. It is possible that the role of siblings may differ in other contexts. It may also differ as children grow older. Furthermore, it may also differ depending on the older siblings' age, something which varied quite considerably in the present study. Future studies will need to address these limitations with longitudinal studies with larger groups of bilingual children, preferably in varying sociolinguistic contexts, and including both subjective and objective measures of children's language proficiency and their exposure.

In sum, our results suggest that older siblings are valuable sources of language input, offering important opportunities for practice, and as such may constitute agents of change in the acquisition of both the majority and the minority language development of bilingual toddlers.

Acknowledgments. We would like to thank all participating families for their time and effort, as well as three anonymous reviewers and the editor for their constructive feedback. This study was completed as part of the first author's MA thesis at Radboud University.

\section{Note}

1. It should be noted that the overall measures of language exposure and use and the measures with parents only also differ in that the former are weighted (i.e., they take into account how much time each interlocutor spends with the child), whereas the latter are not. While this inevitably means that the two are not entirely comparable, the average measures are-to the best of our knowledge, as not all researchers specify exactly how their measures are derived-more comparable to those used in previous research.

\section{References}

Alba, R., Logan, J., Lutz, A., \& Stults, B. (2002). Only English by the third generation? Loss and preservation of the mother tongue among the grandchildren of contemporary immigrants. Demography, 39, 467-484. doi: $10.1353 / \mathrm{dem} .2002 .0023$ 
Barron-Hauwaert, S. (2011). Bilingual siblings. Clevedon: Multilingual Matters.

Barton, M. E., \& Tomasello, M. (1991). Joint attention and conversation in mother-infant sibling triads. Child Development, 62, 517-529. doi: 10.2307/1131127

Berkowitz, C. (2000). Pediatrics: A primary care approach (6th ed.). Elk Grove Village, IL: American Academy of Pediatrics.

Bland, J. M., \& Altman, D. G. (1995). Multiple significance tests: The Bonferroni method. British Medical Journal (Clinical research edition), 310, 170. doi: 10.1136/bmj.310.6973.170

Bornstein, M., Leach, D., \& Haynes, O. M. (2004). Vocabulary competence in first- and second-born siblings of the same chronological age. Journal of Child Language, 31, 855-873. doi: 10.1017/ S0305000904006518

Bridges, K., \& Hoff, E. (2014). Older sibling influences on the language environment and language development of toddlers in bilingual homes. Applied Psycholinguistics, 35, 225-241. doi: 10.1017/ S0142716412000379

Caldas, S. J. (2006). Raising bilingual-biliterate children in monolingual cultures. Clevedon: Multilingual Matters.

Cantone, K. F. (2019). Language exposure in early bilingual and trilingual acquisition. International Journal of Multilingualism. Advance online publication. doi: 10.1080/14790718.2019.1703995

Chatzidaki, A. (1996). Greek as a minority language in Western Europe, "weak" or "strong"? In "Strong" and "weak" languages in the European Union: Aspects of linguistic hegemony (pp. 95-104). Thessaloniki: Centre for the Greek Language [in Greek].

Dale, P. S. (1991). The validity of a parent report measure of vocabulary and syntax at 24 months. Journal of Speech and Hearing Research, 34, 565-571. doi: 10.1044/jshr.3403.565

Dale, P. S., Bates, E., Reznick, J. S., \& Morisset, C. (1989). The validity of a parent report instrument of child language at twenty months. Journal of Child Language, 16, 239-249. doi: 10.1017/s0305000900010394

de Houwer, A. (2007). Parental language input patterns and children's bilingual use. Applied Psycholinguistics, 28, 411-424. doi: 10.1017/S0142716407070221

de Houwer, A. (2009). Bilingual first language acquisition. Clevedon: Multilingual Matters.

Deutsch, W., Wagner, A., Burchardt, R., Schulz, N., \& Nakath, J. (2001). Person in the language of singletons, siblings, and twins. In M. Bowerman \& S. Levinson (Eds.), Language acquisition and conceptual development. Language Culture and Cognition series (pp. 284-315). Cambridge: Cambridge University Press.

Ezeizabarrena, M. J., \& Garcia Fernandez, I. (2018). Length of utterance, in morphemes or in words? MLU3-w, a reliable measure of language development in early Basque. Frontiers in Psychology, 8, 2265. doi: 10.3389/fpsyg.2017.02265

Fenson, L., Marchman, V. A., Thal, D. J., Dale, P. S., Reznick, J. S., \& Bates, E. (2007). MacArthur-Bates communicative development inventories (2nd ed.), Baltimore: Paul H. Brookes.

Field, A. (2009). Discovering statistics using SPSS (3rd ed.), London: Sage.

Gathercole, V. C. M., \& Thomas, E. M. (2009). Bilingual first-language development: Dominant language takeover, threatened minority language take-up. Bilingualism: Language and Cognition, 12, 213-237. doi: $10.1017 /$ S1366728909004015

Gogonas, N., \& Kirsch, C. (2016). "In this country my children are learning two of the most important languages in Europe": Ideologies of language as a commodity among Greek migrant families in Luxembourg. International Journal of Bilingual Education and Bilingualism, 21, 426-438. doi: 10. 1080/13670050.2016.1181602

Gollan, T. H., Starr, J., \& Ferreira, V. S. (2015). More than use it or lose it: The number-of-speakers effect on heritage language proficiency. Psychonomic Bulletin \& Review, 22, 147-155. doi: 10.3758/s13423-014-0649-7

Gutiérrez-Clellen, V. F., \& Kreiter, J. (2003). Understanding child bilingual acquisition using parent and teacher reports. Applied Psycholinguistics, 24, 267-288. doi: 10.1017/S0142716403000158

Hoff, E. (2003). The specificity of environmental influence. Socio-economic status affects early vocabulary development via maternal speech. Child Development, 74, 1368-1378. doi: 10.1111/1467-8624.00612

Hoff, E., Core, C., Place, S., Rumiche, R., Señor, M., \& Parra, M. (2012). Dual language exposure and early bilingual development. Journal of Child Language, 39, 1-27. doi: 10.1017/S0305000910000759

Holmes, J., Roberts, M., Verivaki, M., \& Aipolo, A. (1993). Language maintenance and shift in three New Zealand speech communities. Applied Linguistics, 14, 1-24. doi: 10.1093/applin/14.1.1

Jia, G., \& Fuse, A. (2007). Acquisition of English grammatical morphology by native mandarin-speaking children and adolescents: age-related differences. Journal of speech, language, and hearing research: JSLHR, 50(5), 1280-1299. doi: 10.1044/1092-4388(2007/090) 
Kennedy, K. D., \& Romo, H. D. (2013). "All colors and hues": An autoethnography of a multiethnic family's strategies for bilingualism and multiculturalism. Family Relations, 62, 109-124. doi: 10.1111/j.17413729.2012.00742.x

Kheirkhah, M. (2016). From family language practices to family language policies: Children as socializing agents. Linköping Studies in Arts and Science No. 676. doi: 10.3384/diss.diva-126178

Kheirkhah, M., \& Cekaite, A. (2018). Siblings as language socialization agents in bilingual families. International Multilingual Research Journal, 12, 255-272. doi: 10.1080/19313152.2016.1273738

Kopeliovich, S. (2010). Family language policy: A case study of a Russian-Hebrew bilingual family: Toward a theoretical framework. Diaspora, Indigenous, and Minority Education, 4, 162-178. doi: 10.1080/ 15595692.2010 .490731

Kopeliovich, S. (2013). Happylingual: A family project for enhancing and balancing multilingual development. In M. Schwartz \& A. Verschik (Eds.), Successful family language policy: Parents, children and educators in interaction (pp. 249-275). Dordrecht, Netherlands: Springer.

Lakens, D. (2016, February 14). Why you don't need to adjust your alpha level for all tests you'll do in your lifetime. [Blog post]. Retrieved from http://daniellakens.blogspot.com/2016/02/why-you-dont-need-toadjust-you-alpha.html

Marchman, V. A., \& Martínez-Sussmann C. (2002). Concurrent validity of caregiver/parent report measure of language for children who are learning both English and Spanish. Journal of Speech, Language, and Hearing Research, 45, 983-997. doi: 10.1044/1092-4388(2002/080).

Markodimitraki, M., Papailiou, C., Politimou, N., \& Franco, F. (2015). MB-CDI Words \& Gestures, Greek Adaptation. Retrieved from https://mb-cdi.stanford.edu/adaptations.html.

Melo-Pfeifer, S. (2014). The role of the family in heritage language use and learning: impact on heritage language policies. International Journal of Bilingual Education and Bilingualism, 18(1), 26-44. doi: 10. $1080 / 13670050.2013 .868400$

Oshima-Takane, Y., Goodz, E., \& Derevensky, J. (1996). Birth order effects on early language development: Do secondborn children learn from overheard speech? Child Development, 67, 621-634. doi: $10.2307 / 1131836$

Palermo, F., Mikulski, A. M., Fabes, R. A., Hanish, L. D., Martin, C. L., \& Starget, L. E. (2014). English exposure in the home and classroom: Predictions to Spanish-speaking preschoolers' English vocabulary skills. Applied Psycholinguistics, 35, 1163-1187. doi: 10.1017/S0142716412000732

Park, S. M., \& Sarkar. M. (2007). Parents' attitudes toward heritage language maintenance for their children and their efforts to help their children maintain the heritage language: A case study of Korean-Canadian immigrants. Language, Culture and Curriculum, 20, 223-235. doi: 10.2167/lcc337.0

Pearson, B. Z. (2007). Social factors in childhood bilingualism in the United States. Applied Psycholinguistics, 28, 399-410. doi: 10.1017/S014271640707021X

Place, S., \& Hoff, E. (2011). Properties of dual language exposure that influence two-year-olds' bilingual proficiency. Child Development, 82, 1834-1849. doi: 10.1111/j.1467-8624.2011.01660.x

Prevoo, M. J. L., Mesman, J., Van IJzendoorn, M. H., \& Pieper, S. (2011). Bilingual toddlers reap the language they sow: ethnic minority toddlers' childcare attendance increases maternal host language use. Journal of Multilingual and Multicultural Development, 32(6), 561-576. doi: 10.1080/01434632. 2011.609279

Rojas, R., Iglesias, A., Bunta, F., Goldstein, B., Goldenberg, C., \& Reese, L. (2016). Interlocutor differential effects on the expressive language skills of Spanish-speaking English learners. International Journal of Speech-Language Pathology, 18, 166-177. doi: 10.3109/17549507.2015.1081290

Scheele, A. F., Leseman, P. P. M., \& Mayo, A. Y. (2010). The home language environment of monolingual and bilingual children and their language proficiency. Applied Psycholinguistics, 31, 117-140. doi: 10. 1017/S014271640999019

Shin, S. (2002). Birth order and the language experience of bilingual children. TESOL Quarterly, 36, 103-113. doi: $10.2307 / 3588366$

Skeat, J., Wake, M., Reilly, S., Eadie, P., Bretherton, L., Bavin, E. L., \& Ukoumunne, O. C. (2010). Predictors of early precocious talking: A prospective population study. Journal of Child Language, 37, 1109-1021. doi: 10.1017/S030500090999016X

Smolicz, J., Secombe, M., \& Hudson, D. (2001). Family collectivism and minority languages as core values of culture among ethnic groups in Australia. Journal of Multilingual and Multicultural Development, 22, 152-172. doi: 10.1080/01434630108666430 
Sorenson Duncan, T., \& Paradis, J. (2020). Home language environment and children's second language acquisition: The special status of input from older siblings. Journal of Child Language. Advance online publication. doi: 10.1017/S0305000919000977

Stevens, G., \& Ishizawa, H. (2007). Variation among siblings in the use of a non-English language. Journal of Family Issues, 28, 1008-1025. doi: 10.1177/0192513X07301433

Taylor, K., \& Kan, P. (2018). The impact of older siblings on vocabulary learning in bilingual children. International Journal of Bilingual Education and Bilingualism. Advance online publication. doi: 10 . 1080/13670050.2018.1518969

Thordardottir, E. (2011). The relationship between bilingual exposure and vocabulary development. International Journal of Bilingualism, 15, 426-445. doi: 10.1177/1367006911403202

Unsworth, S. (2013). Assessing the role of current and cumulative exposure in simultaneous bilingual acquisition: The case of Dutch gender. Bilingualism: Language and Cognition, 16, 86-110. doi: 10.1017/ S1366728912000284

Unsworth, S. (2016). Quantity and quality of language input in bilingual language development. In E. Nicoladis \& S. Montanari (Eds.), Lifespan perspectives on bilingualism (pp. 136-196). Berlin: Mouton de Gruyter.

Zambrana, I. M., Ystrom, E., \& Pons, F. (2012). Impact of gender, maternal education, and birth order on the development of language comprehension: A longitudinal study from 18 to 36 months of age. Journal of Developmental and Behavioral Pediatrics, 33, 146-155. doi: 10.1097/DBP.0b013e31823d4f83

Zink, I., \& Lejaegere, M. (2002). N-CDIs: Lijsten voor communicatieve ontwikkeling. Aanpassing en hernormering van de MacArthur CDIs van Fenson et al. 1993. Leuven: Acco.

Zyrianova, N. M., Chertkova Yu., D., \& Pankratova, A. A. (2013). The influence of birth order and family size on the relationships between cognitive abilities and personality traits. Procedia--Social and Behavioral Sciences, 86, 262-266. doi: 10.1016/j.sbspro.2013.08.561

\section{Appendix A}

Table A.1. Parents' native language, parental ratings of fluency in their nonnative language, family constellation, and older siblings

\begin{tabular}{|c|c|c|c|c|c|c|}
\hline $\begin{array}{l}\text { Older } \\
\text { siblings }\end{array}$ & $\begin{array}{l}\text { Child's } \\
\text { ID }\end{array}$ & $\begin{array}{l}\text { Age of } \\
\text { older } \\
\text { siblings }\end{array}$ & $\begin{array}{l}\text { Mother's } \\
\text { native } \\
\text { language }\end{array}$ & $\begin{array}{l}\text { Mother's } \\
\text { nonnative } \\
\text { proficiency }\end{array}$ & $\begin{array}{l}\text { Father's } \\
\text { native } \\
\text { language }\end{array}$ & $\begin{array}{c}\text { Father's } \\
\text { nonnative } \\
\text { proficiency }\end{array}$ \\
\hline \multirow[t]{14}{*}{ No } & 8 & & Dutch & 2 & Greek & 3.5 \\
\hline & 5 & & Greek & 1 & Greek & 1 \\
\hline & 32 & & Greek & 1 & Greek & 1 \\
\hline & 19 & & Greek & 2.5 & Greek & 3.5 \\
\hline & 11 & & Greek & 2.5 & Greek & 4 \\
\hline & 18 & & Greek & 3 & Greek & 1 \\
\hline & 14 & & Greek & 3 & Greek & 2 \\
\hline & 23 & & Greek & 3 & Greek & 2 \\
\hline & 6 & & Greek & 3 & Greek & 3 \\
\hline & 15 & & Greek & 3 & Greek & 5 \\
\hline & 21 & & Greek & 3.5 & Dutch & 2 \\
\hline & 34 & & Greek & 3.5 & Greek & 3.5 \\
\hline & 4 & & Greek & 4 & Dutch & 3.5 \\
\hline & 10 & & Greek & 4 & Greek & 4 \\
\hline
\end{tabular}


Table A.1. (Continued)

\begin{tabular}{|c|c|c|c|c|c|c|}
\hline $\begin{array}{l}\text { Older } \\
\text { siblings }\end{array}$ & $\begin{array}{c}\text { Child's } \\
\text { ID }\end{array}$ & $\begin{array}{l}\text { Age of } \\
\text { older } \\
\text { siblings }\end{array}$ & $\begin{array}{l}\text { Mother's } \\
\text { native } \\
\text { language }\end{array}$ & $\begin{array}{c}\text { Mother's } \\
\text { nonnative } \\
\text { proficiency }{ }^{\text {a }}\end{array}$ & $\begin{array}{l}\text { Father's } \\
\text { native } \\
\text { language }\end{array}$ & $\begin{array}{c}\text { Father's } \\
\text { nonnative } \\
\text { proficiency }^{\text {a }}\end{array}$ \\
\hline & 33 & & Greek & 4 & Greek & 4 \\
\hline & 20 & & Greek & 4.5 & Greek & 3.5 \\
\hline & 31 & & Greek & 5 & Dutch & 2.5 \\
\hline & 16 & & Greek & 5 & Greek & 3.5 \\
\hline \multirow[t]{14}{*}{ Yes } & 17 & 6 & Dutch & 3.5 & Greek & 2 \\
\hline & 1 & 8 & Greek & 1 & Dutch & 1 \\
\hline & 12 & 15.5 & Greek & 1 & Dutch & 1 \\
\hline & 30 & 7 & Greek & 1 & Greek & 2 \\
\hline & 29 & 10 & Greek & 1.5 & Dutch & 1 \\
\hline & 27 & 13 & Greek & 2.5 & Greek & 1.5 \\
\hline & 26 & 6 & Greek & 2.5 & Greek & 2.5 \\
\hline & 25 & 5 & Greek & 3 & Dutch & 1.5 \\
\hline & 28 & 9 & Greek & 3 & Greek & 1 \\
\hline & 13 & 5 & Greek & 3 & Greek & 3.5 \\
\hline & 3 & 5 & Greek & 3.5 & Greek & 3.5 \\
\hline & 9 & 4 & Greek & 4 & Dutch & 1 \\
\hline & 2 & 6 & Greek & 5 & Dutch & 2.5 \\
\hline & 7 & 7 & Greek & 5 & Greek & 3.5 \\
\hline
\end{tabular}

Note. ${ }^{a}$ Measured on a 5 -point scale, where $1=$ limited fluency, 2 =fairly fluent, 3 =quite fluent, 4 =very fluent and $5=$ nativelike fluency. When parents rated themselves as being between categories, the values were averaged.

Cite this article: Tsinivits, D. and Unsworth, S. (2021). The impact of older siblings on the language environment and language development of bilingual toddlers. Applied Psycholinguistics 42, 325-344. https://doi.org/10.1017/S0142716420000570 